\title{
Turcot's syndrome and its mode of inheritance
}

\author{
H. ITOH, K. OHSATO ${ }^{1}$, T. YAO, M. IIDA, AND H. WATANABE \\ From the Departments of Surgery I, Internal Medicine II, and Pathology II, Kyushu University Faculty of \\ Medicine, Fukuoka, Japan
}

SUMMARY Two sisters with Turcot's syndrome, in which malignant cerebral neoplasms are associated with colonic polyposis, are presented. Cases reported in the literature, including some familial cases, have also been analysed. In familial cases, sex was unrelated to the occurrence of this disease and it was found only among siblings of the same parents and not in other members of the family. There was consanguinity in the parents of the patients in two out of three families. We therefore concluded that the mode of inheritance in this condition is autosomal recessive and that it is genetically distinct from the ordinary form of familial polyposis coli. Support is lent to the absence of an association between the two disorders by a difference in the number, size, and distribution of the colonic polyps found in Turcot's syndrome as compared with familial polyposis coli.

Turcot's syndrome is a rare hereditary disease in which brain tumour is associated with colonic polyposis. There are two different views on the mode of inheritance of this disease. McKusick (1962) asserted that it is transmitted in the autosomal recessive mode on studying the family reported by Turcot et al. (1959). On the other hand, Smith and Kern (1973) argued that the mode of inheritance is autosomal dominant on the contention that brain tumour represents one of the phenotypes of pleiotropia of familial polyposis coli. The purpose of this paper is to report on two siblings with Turcot's syndrome and to study the mode of inheritance by including the cases reported in the literature.

\section{Case reports}

\section{CASE 1}

A 19-year-old girl was admitted in November 1971 complaining of prolapse of a rectal polyp, haematochezia, and diarrhoea. A diagnosis of diffuse colonic polyposis was made and total colectomy with ileorectostomy was performed. Histopathological examination of the resected material revealed about 100 adenomas ranging from 0.1 to $5.0 \mathrm{~cm}$ in diameter

${ }^{1}$ Address for reprint requests: Dr K. Ohsato, Kyushu University Faculty of Medicine, Department of Surgery I, Maedashi 3-1-1, Fukuoka, Japan 812.

Received for publication 2 November 1978 scattered throughout the colon, 13 of which were larger than $3 \mathrm{~cm}$ in diameter (Fig. 1). Two invasive adenocarcinomas were found in the transverse colon. Upper gastrointestinal series and gastroduodenoscopy revealed a large duodenal adenoma but no gastric polyp was demonstrated. She was admitted again in August 1974 complaining of headache and decrease in visual acuity. On physical examination ptosis of the left eyelid and bilateral papilloedema were found. On carotid angiography, a large less-vascular mass was noted in the left frontal lobe. There were several café-au-lait spots on the skin of the chest, back, abdomen, and extremities, but there were no nodules on the body surface. Radiographic survey of the entire skeleton did not reveal any neoplastic or hyperplastic changes. Panoramic radiography of the mandible and maxilla demonstrated a small opacity in the mandible measuring $2 \mathrm{~mm} \times 3 \mathrm{~mm}$ but no obvious osteoma could be recognised. Subtotal removal of the brain tumour was carried out in September 1974. Histological examination of the material that was removed revealed a grade 3 astrocytoma. The patient died of recurrence of the brain tumour in October 1975. On necropsy, the growth of three independent brain tumours in the bilateral frontal lobes and left temporal lobe was revealed. They were all found to be astrocytoma, grade 3 , histologically. The necropsy also revealed follicle cysts in the bilateral ovaries and an ectopic pancreas in the jejunum. There was no 


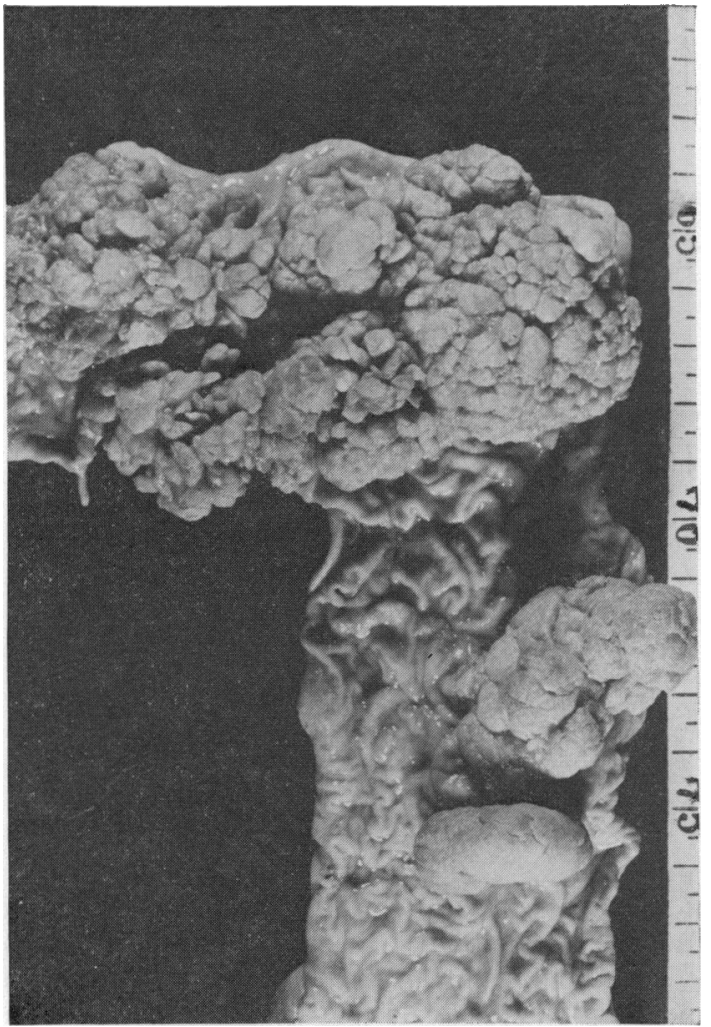

Fig. 1 Case 1. Resected material of the descending colon. Multiple polyps, especially large polyps are observed.

neoplastic tumour in the neck, thorax, or abdomen, except for a small carcinoma in an adenoma in the duodenum and nine adenomas in the retained rectum. This case was described only briefly, since it has already been reported as a case of Turcot's syndrome by Ohsato et al. (1975).

\section{CASE 2}

This patient was the younger sister of case 1 . She was 17 years old when she was admitted in January 1972 complaining of haematochezia. Upper gastrointestinal series, barium-enema study, and endoscopic examination were performed and the diagnosis of colonic polyposis and multiple gastric cancers was established. In February 1972 total gastrectomy and total colectomy were carried out with preservation of the rectum. About 80 adenomas, ranging in size from 0.3 to $5.0 \mathrm{~cm}$, were found distributed throughout the colon (Fig. 2). Adenocarcinoma was found in two large adenomas. Fourteen small primary gastric carcinomas, all being signet-ring-cell carcinomas, were found in the gastric fundic glandular area

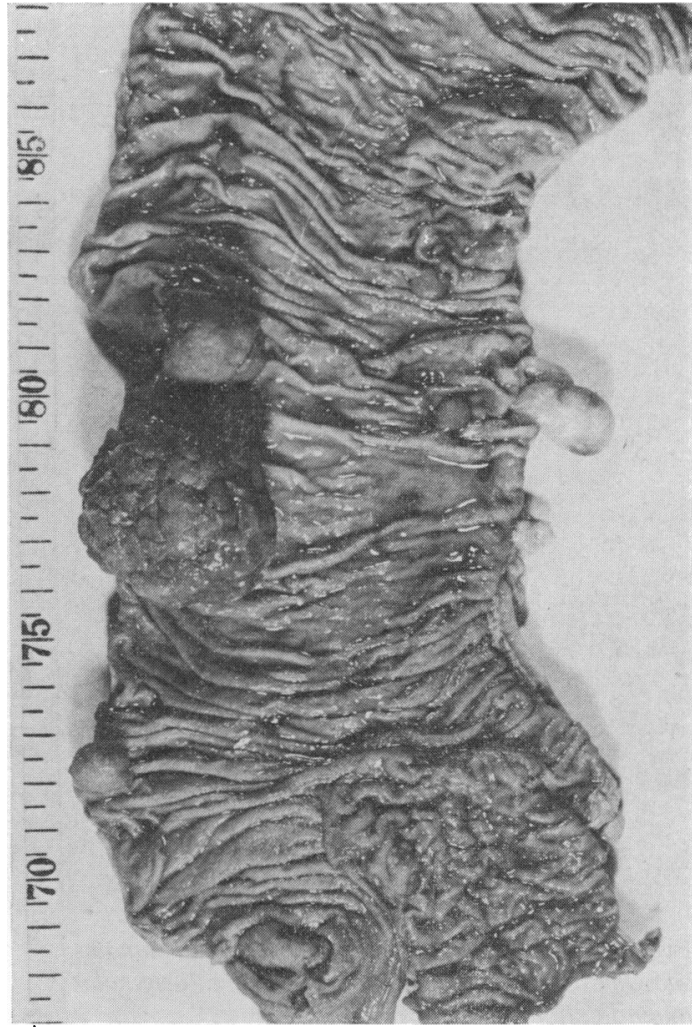

Fig. 2 Case 2. Resected material of the ascending colon, caecum, and terminal ileum.

(Ohsato et al., 1974). Three small subcutaneous tumours were found in the left thigh and one of these was proved to be a lipoma histologically after its removal. The patient recovered and was well until October 1975. From the beginning of 1976, headache and urinary incontinence appeared together with unstable gait. Finger tremor and ptosis of the right eyelid were also noted. Physical examination on readmission revealed several café-au-lait spots on the skin of the back, abdomen, and hip, but there were no palpable nodules except for two lipomas in the left thigh. Neurological examination revealed mental dullness, decrease in visual acuity with bilateral papilloedema, left facial paresis, and hand tremor. Radiographs of the entire skeleton including panoramic radiographs of the jaw revealed no abnormality. Computerised axial tomography of the brain and carotid angiography showed a large mass in the right temporal lobe. As it was so large, only a partial removal of the tumour was attempted and ${ }^{60} \mathrm{Co}$ irradiation of 5400 rads in total was given later. The histology of the resected brain tumour was a 


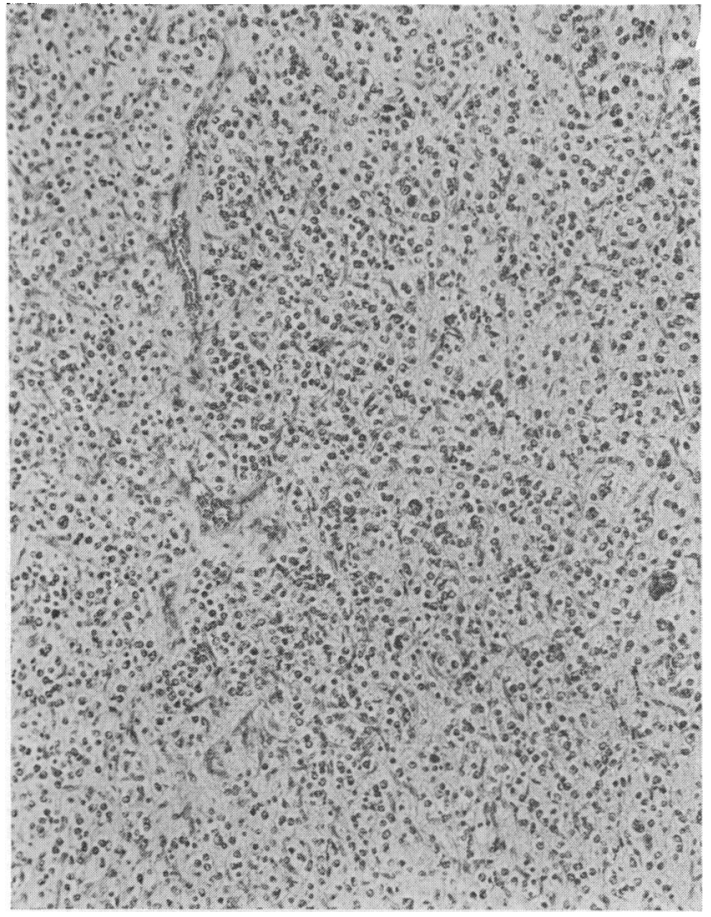

Fig. 3 Case 2. Photomicrograph of brain tumour showing astrocytoma, grade 3 . $H$ and $E$, original magnification $\times 94$.

grade 3 astrocytoma (Fig. 3). She died of recurrence of the brain tumour on 25 September 1977 at her home but necropsy was not performed.

\section{FAMILY HISTORY OF THE PATIENTS}

The pedigree of the family is shown in Fig. 4. The parents of the patients are first cousins. Neither of them had colonic polyp on air-barium doublecontrast enema examination or neurological disorder. However, the father died of lung cancer at the age of 46 years in 1975. His chest was examined in July 1974 when chest radiographs including tomographs were taken; they demonstrated a right hilar mass. Bronchofibreoscopy revealed an endobronchial mass in the right bronchus. It was biopsied and confirmed to be large-cell carcinoma of anaplastic solid type histologically. The patients have a younger brother but he did not have colonic polyp on barium-enema examination nor did he have neurological symptoms.

COMPARATIVE STUDY OF COLONIC POLYPS IN TURCOT'S SYNDROME AND FAMILIAL POLYPOSIS COLI

The number and size of colonic polyps found in cases

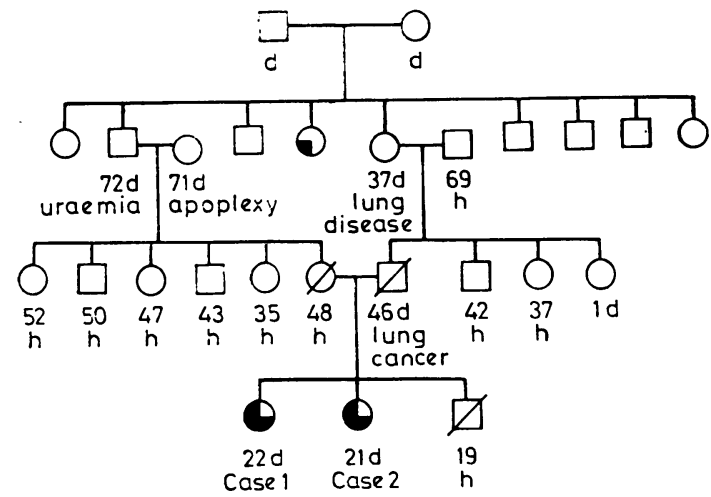

Fig. 4 Family pedigree of the present patients. d: Died. h: Healthy.

Number: Current age or age at death (years).

$\square \bigcirc$ Unaffected or unexamined male $(\square)$ and

female (O).

$\square$ No colonic polyposis on barium-enema examination.

Colonic polyposis.

- Brain tumour.

- Colonic cancer.

of Turcot's syndrome so far reported are shown in Table 1. The number of polyps in the patients reported by Baughman et al. (1969) was two in two and 24 in one case, and that in our cases was 80 in one and 100 in the other. The distribution of polyps in the patients reported by Turcot et al. (1959) was similar to that of our cases as far as we could observe from their photographs. The number of polyps in the case reported by Kawanami et al. (1976) was 85. Thus the number of colonic polyps in Turcot's syndrome appears to be less than that in familial polyposis coli. Among the eight cases in which the size of colonic polyps had been described clearly, there were six patients having a large polyp over $3 \mathrm{~cm}$ in diameter. The ratio of the number of the large polyps to that of all polyps in the colon is frequently more than $1 \%$.

During the past 12 years, we have studied 22 cases of diffuse colonic polyposis, including the number and size of colonic polyps (Table 2). They include 18 cases of familial polyposis coli, two cases suspected of 'recessive adenomatous polyposis', defined by Bussey (1975), and two cases of Turcot's syndrome. The number and size of polyps were obtained from the resected specimens. The large polyp which was over $3 \mathrm{~cm}$ in diameter included adenoma and carcinoma in adenoma. The ratio of the number of large polyps over $3 \mathrm{~cm}$ in diameter to that of all polyps in the colon was calculated. The ratio in familial polyposis coli was less than $0.2 \%$, but that of 'recessive adenomatous polyposis' and Turcot's syndrome 
Turcot's syndrome and its mode of inheritance

Table 1 Summary of reported cases of cerebrospinal tumour with colonic polyposis

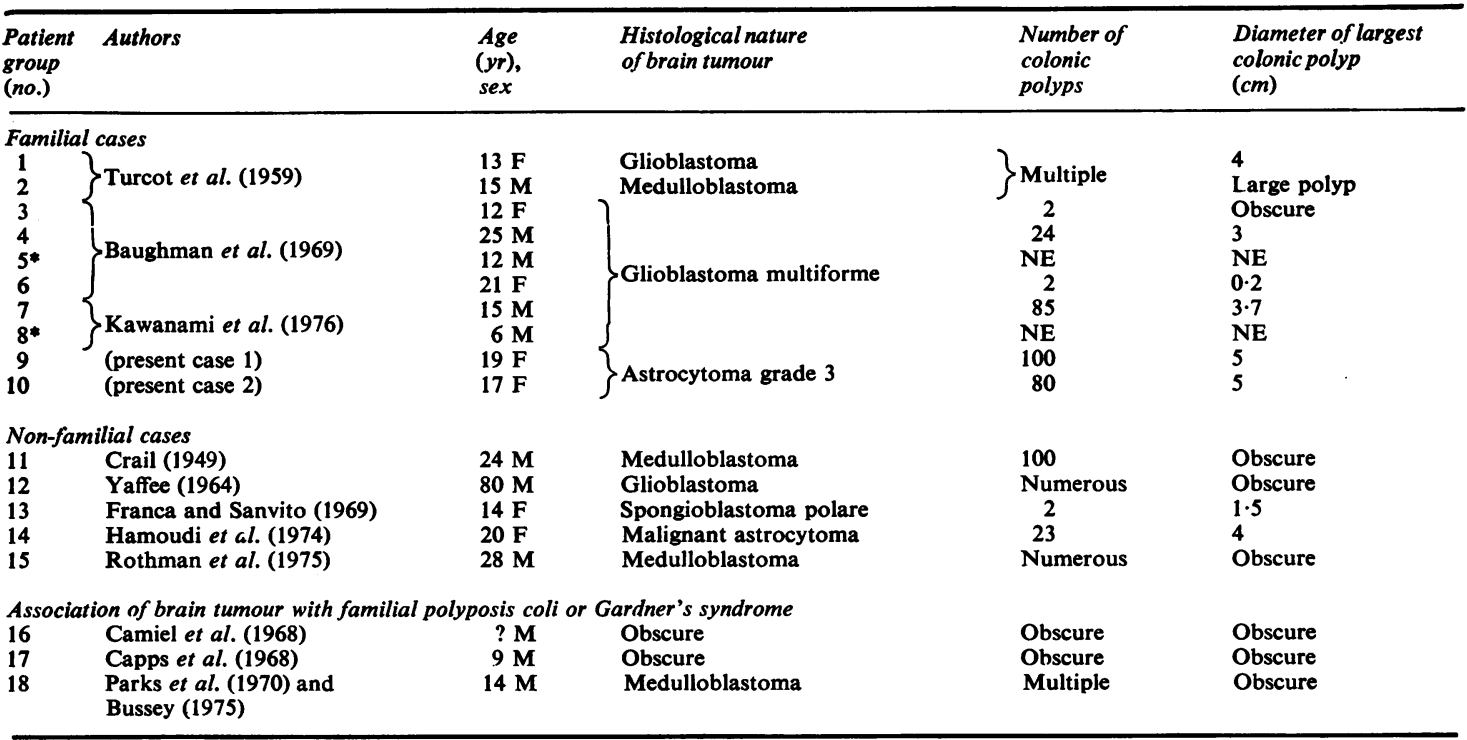

-Turcot's syndrome was suspected but the colonic lesion was not examined.

NE: not examined.

Table 2 Distribution of colonic polyps in cases with diffuse colonic polyposis

\begin{tabular}{|c|c|c|c|c|c|}
\hline Patient no. & $\begin{array}{l}\text { Age }(y r), \\
\text { sex }\end{array}$ & Hereditary trait & $\begin{array}{l}\text { Number of colonic } \\
\text { polyps } \\
\text { (A) }\end{array}$ & $\begin{array}{l}\text { Number of polyps over } \\
3 \mathrm{~cm} \text { in diameter } \\
\text { (B) }\end{array}$ & $\frac{(B)}{(A)} \times 100$ \\
\hline $\begin{array}{r}1 \\
2 \\
3 \\
4 \\
5 \\
6 \\
7 \\
8 \\
9 \\
10 \\
11 \\
12 \\
13 \\
14 \\
15 \\
16 \\
17 \\
18\end{array}$ & $\begin{array}{l}57 \mathrm{M} \\
23 \mathrm{~F} \\
37 \mathrm{M} \\
31 \mathrm{M} \\
42 \mathrm{M} \\
22 \mathrm{~F} \\
41 \mathrm{M} \\
12 \mathrm{~F} \\
9 \mathrm{~F} \\
26 \mathrm{M} \\
37 \mathrm{M} \\
27 \mathrm{~F} \\
18 \mathrm{~F} \\
38 \mathrm{M} \\
41 \mathrm{~F} \\
26 \mathrm{~F} \\
27 \mathrm{~F} \\
24 \mathrm{M}\end{array}$ & $\begin{array}{l}\text { Familial } \\
\text { Nonfamilial }\end{array}$ & $\begin{array}{r}1000 \\
603 \\
>10000 \\
>10000 \\
>10000 \\
489 \\
>10000 \\
70 \\
183 \\
>10000 \\
971 \\
910 \\
350 \\
>10000 \\
>10000 \\
>10000 \\
4000 \\
500\end{array}$ & $\begin{array}{l}0 \\
1 \\
3 \\
2 \\
1 \\
0 \\
0 \\
0 \\
0 \\
4 \\
0 \\
0 \\
0 \\
1 \\
6 \\
5 \\
0 \\
0\end{array}$ & $\begin{array}{l}0 \\
0.17 \\
0.03 \\
0.02 \\
0.01 \\
0 \\
0 \\
0 \\
0 \\
0.04 \\
0 \\
0 \\
0 \\
0.01 \\
0.06 \\
0.05 \\
0 \\
0\end{array}$ \\
\hline $\begin{array}{l}19^{*} \\
20^{*}\end{array}$ & $\begin{array}{l}40 \mathrm{M} \\
20 \mathrm{~F}\end{array}$ & Nonfamilial & $\begin{array}{r}101 \\
50\end{array}$ & ${ }_{4}^{1 \dagger}$ & $\begin{array}{l}1.0 \\
8.0\end{array}$ \\
\hline $\begin{array}{l}\text { Present report } \\
21 \text { (case 1) } \\
22 \text { (case 2) }\end{array}$ & $\begin{array}{l}19 \mathrm{~F} \\
17 \mathrm{~F}\end{array}$ & Familial & $\begin{array}{r}100 \\
80\end{array}$ & $\begin{array}{r}13 \\
2\end{array}$ & $\begin{array}{r}13.0 \\
2.5\end{array}$ \\
\hline
\end{tabular}

*Suspected of 'recessive adenomatous polyposis'.

†Polyp in vermiform appendix.

was more than $1 \%$. In the early stage of familial polyposis coli, as it can be seen in patients 8 and 9 in Table 2, the number of polyps may be less than 200 but the size of the polyps is very small. Thus, it appears that, compared with familial polyposis coli, colonic polyps in Turcot's syndrome are fewer in number but are larger in size. 


\section{Discussion}

Familial polyposis coli is frequently associated with a wide variety of extracolonic tumour-that is, in bones, soft tissues, upper gastrointestinal tract, and other sites (Hoffmann and Goligher, 1971; Bussey, 1975). Incidental association of brain tumour with familial polyposis coli may also occur. Smith and Kern (1973) speculated that brain tumour represents one of the phenotypes of a dominant gene capable of producing familial multiple polyposis which is transmitted in the autosomal dominant mode. McKusick (1962) and Baughman et al. (1969), however, after a study of the family pedigrees, suggested that the mode of inheritance was autosomal recessive. As only a small number of familial cases of Turcot's syndrome have been found, it has been difficult to determine which of the two modes of inheritance is actually responsible for its transmission.

To our knowledge, 18 patients in 12 families have been reported to have Turcot's syndrome as described in Table 1. Among these, the patients have been reported to be familial cases in only three studies-that is, studies by Turcot et al. (1959), Baughman et al. (1969), and us. In these three families, the disease is found in both sexes but only among siblings. Neither colonic polyposis nor brain tumour was found in the parents or other members of these families except for a posterior-fossa ependymoma in a 3-year-old girl who was a second cousin of the patients reported by Baughman et al. (1969). McKusick (1962) stated that the parents of the patients reported by Turcot $e t$ al. were third cousins, and since our patients' parents are first cousins, consanguinity is demonstrated in two of the three families. The occurrence in both sexes, but only among siblings, and consanguinity in the parents of the patients indicate an autosomal recessive mode of inheritance of Turcot's syndrome. Kawanami et al. (1976) reported two siblings who were suspected of Turcot's syndrome. One of the patients was a 15year-old boy who suffered from brain tumour associated with colonic polyposis. His elder brother had died of brain tumour at the age of 10 years but no examination of the colonic lesions was made. Neither colonic polyposis nor brain tumour was found in other members of the family. The mode of inheritance in this family resembles that of the above three familial cases.

Besides these familial cases, non-familial occurrence of brain tumour associated with colonic polyposis is found in five patients (Crail, 1949; Yaffee, 1964; Franca and Sanvito, 1969; Hamoudi et al., 1974; Rothman et al., 1975). Neither colonic polyposis nor brain tumour has been found in other members of the patients' family, except in Yaffee's case in which Gardner's stigmata were found in the husband of the aunt of the patient who is not related by blood. Therefore the mode of inheritance is considered to be autosomal recessive. On the other hand, in the cases of Camiel et al. (1968), Capps et al. (1968) and Parks et al. (1970) brain tumour developed together with colonic polyposis within the wellconfirmed pedigrees of familial polyposis coli. As they include many patients suffering from colonic polyposis, but as no one else in the family has brain tumour, association of brain tumour with colonic polyposis in these three patients seems to be coincidental. In these cases the brain tumours could be one of the phenotypes of pleiotropia of familial polyposis coli.

(1) In Turcot's syndrome the manifestations of brain tumour and colonic polyposis are significantly associated and are not merely coincidental, although the association of brain tumour is only incidental in the few cases of familial polyposis coli. (2) Moreover, an autosomal recessive mode of transmission is most likely in this syndrome. (3) The number of colonic polyps in Turcot's syndrome was frequently less than 100 , in contrast with the study of Bussey (1975) who noted that the average number of polyps in familial polyposis coli was about 1000 and rarely less than 200. The analysis of macroscopic findings of colonic polyps showed that they were fewer in number and larger in size in Turcot's syndrome compared with familial polyposis coli. (4) Therefore, we present the hypothesis that Turcot's syndrome is genetically distinct from familial polyposis coli.

We wish to thank Professor F. Nakayama, Department of Surgery I, Kyushu University Faculty of Medicine, for his valuable help in preparing the manuscript. We also thank the Ohmuta City Hospital for the valuable information on the clinical findings of the patients' father and Department of Neurosurgery, Kyushu University Faculty of Medicine, for the information regarding the brain tumours of the siblings in the case report.

\section{References}

Baughman, F. A., Jr, List, C. F., Williams, J. R., Muldoon, J. P., Segarra, J. M., and Volkel, J. S. (1969). The gliomapolyposis syndrome. New England Journal of Medicine, 281, 1345-1346.

Bussey, H. J. R. (1975). Familial Polyposis Coli. Johns Hopkins University Press: Baltimore.

Camiel, M. R., Mulé, J. E., Alexander, L. L., and Benninghoff, D. L. (1968). Association of thyroid carcinoma with Gardner's syndrome in siblings. New England Journal of Medicine, 278, 1056-1058.

Capps, W. F., Jr, Lewis, M. I., and Gazzaniga, D. A. (1968). Carcinoma of the colon, ampulla of Vater and urinary bladder associated with familial multiple polyposis. Diseases of the Colon and Rectum, 11, 298-305. 
Crail, H. W. (1949). Multiple primary malignancies arising in the rectum, brain, and thyroid: report of a case. United States Naval Medical Bulletin, 49, 123-128.

Franca, L. C. M., and Sanvito, W. L. (1969). Tumor maligno do sistema nervoso central associado a polipose do colon com degeneracao maligna. Arquivos de Neuro-Psiquiatria, 27, 67-72.

Hamoudi, A. B., Ertel, I., Newton, W. A., Jr, Reiner, C. B., and Clatworthy, H. W., Jr. (1974). Multiple neoplasms in an adolescent child associated with $\operatorname{IgA}$ deficiency. Cancer, 33, 1134-1144.

Hoffmann, D. C., and Goligher, J. C. (1971). Polyposis of the stomach and small intestine in association with familial polyposis coli. British Journal of Surgery. 58, 126-128.

Kawanami, K., Ohno, M., Matsuura, K., Soejima, T., Kitamura, K., Watanabe, H., and Enjoji, M. (1976). Turcot's syndrome, report of an autopsy case. Stomach and Intestine, 11, 1075-1082.

McKusick, V. A. (1962). Genetic factors in intestinal polyposis. Journal of the American Medical Association, 182, 271-277.

Ohsato, K., Hashimoto, H., Itoh, H., Kinoshita, K., Cheng, C., Yao, T., and Watanabe, H. (1975). Familial adenomatosis of the colon associated with brain tumor (Turcot's syndrome): report of a case and review of the literature. Stomach and Intestine, 10, 1511-1517.

Ohsato, K., Watanabe, H., Itoh, H., Yao, T., and Nishimura, M. (1974). Simultaneous occurrence of multiple gastric carcinomas and familial polyposis of the colon. Japanese Journal of Surgery, 4, 165-174.

Parks, T. G., Bussey, H. J. R., and Lockhart-Mummery, H. E. (1970). Familial polyposis coli associated with extracolonic abnormalities. Gut, 11, 323-329.

Rothman, D., Su, C. P., and Kendall, A. B. (1975). Dilemma in a case of Turcot's (glioma-polyposis) syndrome: report of a case. Diseases of the Colon and Rectum, 18, 514-515.

Smith, W. G., and Kern, B. B. (1973). The nature of the mutation in familial multiple polyposis: Papillary carcinoma of the thyroid, brain tumors, and familial multiple polyposis. Diseases of the Colon and Rectum, 16, 264-271.

Turcot, J., Després, J. P., and St. Pierre, F. (1959). Malignant tumors of the central nervous system associated with familial polyposis of the colon. Diseases of the Colon and Rectum, 2, 465-468.

Yaffee, H. S. (1964). Gastric polyposis and soft tissue tumors: A variant of Gardner's syndrome. Archives of Dermatology, 89, 806-808. 